\title{
Bernard Noël, Artaud et Paule
}

\author{
Ida Merello
}

\section{(2) OpenEdition}

\section{Journals}

\section{Edizione digitale}

URL: http://journals.openedition.org/studifrancesi/30828

DOI: 10.4000/studifrancesi.30828

ISSN: 2421-5856

\section{Editore}

Rosenberg \& Sellier

\section{Edizione cartacea}

Data di pubblicazione: 1 avril 2006

Paginazione: 194

ISSN: 0039-2944

\section{Notizia bibliografica digitale}

Ida Merello, «Bernard Noël, Artaud et Paule», Studi Francesi [Online], 148 (XLX | I) | 2006, online dal 30 novembre 2015, consultato il 19 avril 2021. URL: http://journals.openedition.org/studifrancesi/30828 ; DOI: https://doi.org/10.4000/studifrancesi.30828

Questo documento è stato generato automaticamente il 19 avril 2021.

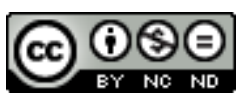

Studi Francesi è distribuita con Licenza Creative Commons Attribuzione - Non commerciale - Non opere derivate 4.0 Internazionale. 


\title{
Bernard Noël, Artaud et Paule
}

\author{
Ida Merello
}

\section{NOTIZIA}

Bernard Noël, Artaud et Paule, Torino, I libri dell' Arca, Joker 2005, pp. 64.

1 L'editore Joker, specializzato in pubblicazioni di nicchia, offre questa volta al pubblico un testo militante di Bernard Noël, che introduce con una lunga prefazione la testimonianza di Paule Thévenin, Antonin Artaud nella mia vita. Il poeta, che ha ben conosciuto Paule Thévenin, ricorda come Artaud le abbia consegnato prima di morire il corpus della sua scrittura, ossia una quantità di quaderni da decifrare per portarli alle stampe, e come il compito sia stato proseguito dalla donna fino alla morte, nonostante l'opposizione della famiglia di Artaud attenta ai diritti d'autore e gelosa della proprietà. A seguire, Marco DOTTI ripercorre la storia dell'incontro tra la Thévenin e Artaud, al momento in cui questi, duramente provato dopo gli anni di internamento, è comunque appassionatamente rivolto all'attività artistica ed editoriale, e cita Fernand Pouey, responsabile delle trasmissioni culturali della Radiodiffusion française, a conferma dello scrupolo con cui Artaud preparò l'edizione radiofonica di Pour en finir avec le jugement de Dieu, impegnato ormai a una totale reinvenzione della forma. 